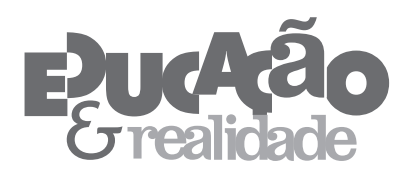

\title{
Apresentação Ensino de Sociologia: novas temáticas e experiências internacionais
}

\author{
Amurabi Pereira de Oliveira' \\ 'Universidade Federal de Alagoas (UFAL), Alagoas/AL - Brasil
}

Como já se convencionou apontar, o Ensino de Sociologia na Educação Básica no Brasil possui alguns marcos históricos, como os pareceres de Rui Barbosa e a Reforma Benjamin Constant ainda no século XIX que indicavam a introdução dessa ciência na escola, porém isso apenas se concretizou a partir dos anos de 1920 por meio das reformas Rocha Vaz (1925) e Francisco Campos (1931) nas quais ocorreu a introdução efetiva dessa disciplina nos currículos escolares, ainda que se deva destacar a experiência pontual do Atheneu Sergipense em Aracaju no final do século XIX (Oliveira, 2013). Neste período, como não havia agencias formadoras em Ciências Sociais - que começam a surgir a partir de 1933 em São Paulo - os primeiros professores dessa área eram, via de regra, autodidatas em termos acadêmicos, responsáveis também pelo processo de rotinização do conhecimento sociológico difundido pelo substancial número de manuais produzidos no período (Meucci, 2011).

O ano de 1942, quando ocorreu a Reforma Capanema, também é emblemático na discussão que se levanta aqui, uma vez que a Sociologia é retirada do currículo, o que é interpretado por alguns autores como um acontecimento motivado por questões ideológicas, já que a disciplina seria supostamente subversiva, porém, olvida-se nessa argumentação o caráter conservador que a Sociologia assumia nesse momento nas escolas, além da indefinição de seu papel no novo currículo que emergia nesse momento, o que levou a uma longa ausência, que se aprofundou no período da ditadura militar, ante a profissionalização compulsória do currículo escolar do Ensino Médio (Santos, 2004). Com o processo de redemocratização, a Sociologia retornou às escolas de forma pontual, o que é acompanhado por campanhas pela reintrodução dessa disciplina, capitaneado inicialmente por instituições profissionais, e não pelas acadêmicas (Moraes, 2011). Com a promulgação da nova Lei de Diretrizes e Bases da Educação (LDB), em 1996, o Ensino de Sociologia toma novos contornos, uma vez que em seu artigo 36, parágrafo $1^{\circ}$, inciso III institui-se que o aluno ao final do Ensino Médio deveria demonstrar: “[...] domínio dos conhecimentos de Filosofia e de Sociologia necessários ao exercício da cidadania”, o que não foi suficiente para garantir um espaço para a Sociologia enquanto disciplina escolar, sendo tal cenário confir-

Educação \& Realidade, Porto Alegre, v. 39, n. 1, p. 11-16, jan./mar. 2014.

Disponível em: <http://www.ufrgs.br/edu_realidade> 
Apresentação da Seção Temática - Ensino de Sociologia

mado posteriormente com os Parâmetros e Diretrizes Curriculares Nacionais para o Ensino Médio, publicados no final dos anos de 1990.

O processo paulatino de reintrodução da Sociologia na escola mostrou-se, portanto, não linear, marcado por avanços e retrocessos, e por um cenário nacional substancialmente heterogêneo, uma vez que enquanto alguns estados já contavam com essa disciplina já nos anos de 1980 e início de 1990, outros ainda não vislumbravam essa possibilidade até recentemente. Também ações mais pontuais são emblemáticas nesse contexto, como a introdução da Sociologia no vestibular da Universidade Federal de Uberlândia em 1997, que impactou diretamente a forma como essa disciplina passa a ser encarada naquele contexto, apontando para a íntima relação entre a legitimidade de uma dada disciplina escolar e os exames de admissão do ensino superior.

Do que foi apontado até aqui duas questões merecem destaques: a) principalmente a partir da nova LDB houve a construção de um forte discurso que liga o Ensino de Sociologia à formação para a cidadania, que como poderá ser observado ao longo desse dossiê, ao considerarmos os trabalhos desenvolvidos em outros países, não se trata de uma quadro isolado do Brasil, todavia, a nova LDB forjada no cenário pósditadura certamente percebe a Educação como um importante instrumento para a consolidação da democracia e da cidadania (Weber, 1996), e a Sociologia tende a ocupar um lugar especial nessa interpretação; b) o cenário não linear desta ciência no currículo escolar também implicou em uma produção científica descontinuada, tendo em vista que as pesquisas surgem mais nos períodos em que a Sociologia aparece na escola (Silva, 2010), de modo que houve um verdadeiro "insulamento acadêmico" (Sarandy, 2012) dessa questão, tanto no campo da Educação, como também, e principalmente, no campo das Ciências Sociais.

Outros desdobramentos que merecem destaque são a publicação das Orientações Curriculares Nacionais de Sociologia (OCN), e a elaboração do Parecer CNE/CBE no 38 , que institui a obrigatoriedade do Ensino de Sociologia e Filosofia no Brasil, ambos no ano de 2006, as OCN em particular tiveram o mérito de incitar um deslocamento no foco do Ensino de Sociologia, da formação para a cidadania para o processo de estranhamento e desnaturalização da realidade social. Em 2008 ocorreu a promulgação da lei no 11.684 que tornou obrigatório o Ensino de Sociologia e Filosofia em todas as séries do Ensino Médio, e mais recentemente a Sociologia foi incluída no Plano Nacional do Livro Didático, iniciando sua distribuição nas escolas em 2012, tendo sido selecionados dois livros: Sociologia para o Ensino Médio de Nelson Tomazi, e Tempos Modernos, Tempos de Sociologia de Helena Bomeny e Bianca Freire-Medeiros.

Concomitante aos avanços institucionais, no plano acadêmico o cenário também tem se transformado. Nos últimos anos têm ocorrido um incremento substancial na produção acadêmica desenvolvida em nível de pós-graduação em torno dessa temática, por mais que em números totais ela ainda seja tímida, concentrada principalmente nos Programas de Educação (Handfas, 2011), todavia, o espaço junto aos Programas de Ciências Sociais/Sociologia têm sido ampliado, destacando-se a 
criação da linha de pesquisa em Ensino de Sociologia junto ao Programa de Pós-Graduação em Ciências Sociais da Universidade Estadual de Londrina em 2011, e do Mestrado Profissional em Ciências Sociais para o Ensino Médio da Fundação Joaquim Nabuco, em 2012. Também os fóruns para discussão e divulgação das pesquisas acadêmicas neste âmbito foram ampliados, em 2005 criou-se o Grupo de Trabalho intitulado Ensino de Sociologia, cujas atividades se desenvolvem junto ao Congresso Brasileiro de Sociologia, em 2009 o Encontro Nacional sobre o Ensino de Sociologia na Educação Básica e em 2012 ocorre a fundação da Associação Brasileira de Ensino de Ciências Sociais, que promoveu seu primeiro congresso em 2013, além de uma série de eventos regionais, estaduais e locais que têm discutido este tema.

Apesar das questões apontadas acima percebemos que a produção acadêmica brasileira sobre o Ensino de Sociologia ainda possui uma inexpressiva inserção internacional, e um diálogo praticamente inexistente com as pesquisas de outros países. A ideia deste dossiê temático surgiu durante o Second International Sociological Association Forum of Sociology, que ocorreu em 2012 na cidade de Buenos Aires, Argentina, no qual coordenei a sessão temática intitulada Teachers and Teaching of Social Sciences in Latin America, que se mostrou como um interessante espaço de discussão e troca de experiências sobre o Ensino de Sociologia em diferentes países, e apesar dos contextos distintos, que traziam consigo características bastante idiossincráticas, havia claramente pontos em comum, o que poderá ser percebido na leitura desse número. O que se almeja aqui é que o leitor possa, por um lado, apropria-se de novas discussões que têm emergido em torno do Ensino de Sociologia no Brasil, por outro, ter acesso às discussões dessa temática em outros países, realizando um exercício comparativo.

O trabalho de Amaury Moraes, Ciência e Ideologia na Prática dos Professores de Sociologia no Ensino Médio: da neutralidade impossível ao engajamento indesejável, ou seria o inverso?, nos remete a questões fundamentais no campo educacional, que tomam contornos sui generis no caso do Ensino da Sociologia, na medida que se tencionam caminhos possíveis a serem seguidos, segundo o autor ao menos três se colocam de imediato: a) o risco de que essa disciplina não seja ensinada como ciência, mas sim como um discurso ideológico; b) o reconhecimento de que não há neutralidade possível, e que a Sociologia deve ser ensinada tendo em vista a produção de uma consciência que vise transformar a realidade; c) ela deveria ser lecionada proporcionando uma alfabetização científica dos educandos do Ensino Médio. Com essa reflexão Moraes nos traz para questões que ainda são um impasse no Ensino de Sociologia, que remetem à tradição de pensamento dessa ciência no Brasil, mas que ainda não foram devidamente encaradas pelos pesquisadores na área.

Em Campo Científico-Acadêmico e a Disciplina de Sociologia na Escola, Célia Caregnato e Victoria Cordeiro se propõem a realização de um balanço em torno da produção acadêmica desenvolvida em nível de pós-graduação sobre o Ensino de Sociologia, porém, não se trata simplesmente de realizar um estado da arte no sentido mais estrito, pois a preocupação das autoras, a partir das categorias de campo e habitus de

Educação \& Realidade, Porto Alegre, v. 39, n. 1, p. 11-16, jan./mar. 2014.

Disponível em: <http://www.ufrgs.br/edu_realidade> 
Apresentação da Seção Temática - Ensino de Sociologia

Bourdieu, é acompanhar o movimento de formação de um campo científico no Brasil, que se mobiliza a partir de um conjunto de questões, identificado pelas autoras em três temáticas principais: a) os desafios para a atuação profissional de graduados em ciências sociais; b) relação entre disciplina científica e escolar; c) a disciplina sociologia na ótica dos atores da escola.

Juarez Lopes de Carvalho Filho, em O Ensino de Sociologia como Problema Epistemológico e Sociológico, inicia uma discussão em um esforço comparativo entre a França e o Brasil, o que é praticamente inexistente na literatura nessa área, salvo o trabalho Leithauser e Weber (2010) no qual comparam a perspectiva sobre o ensino de Sociologia entre professores do Brasil e da Alemanha. A escolha pela França mostra-se perspicaz não apenas pelo fato dela ter sido o berço da Sociologia, mas também pelo forte impacto que a ciência desenvolvida neste país teve nas décadas iniciais da Sociologia brasileira, período no qual essa disciplina se institucionalizava no currículo escolar. Ele observa que tanto no Brasil quanto na França o ensino da sociologia se revela como problema social e político, na medida em que a conjuntura social na qual se encontram os professores e os alunos exerce uma influência direta sobre o ensino.

Educação Antirracista: tensões e desafios para o ensino de sociologia, de autoria de Luiz Fernandes de Oliveira, nos remete para além do Ensino de Sociologia a outra questão emergente no campo educacional brasileiro: o debate sobre as relações étnico-raciais na escola, o que tem sido colocado como uma pauta relevante de pesquisas, que têm ganhado uma substancial visibilidade ao menos desde a lei $\mathrm{n}^{\circ} 10.639 / 03$, que institui o ensino de História e Culturas Afro-Brasileiras na Educação Básica. Oliveira pensa os professores de Sociologia como intelectuais públicos, e enquanto tais deveriam operar um diálogo e uma intervenção na realidade social dos jovens estudantes e no mundo, e buscar revelar o racismo estrutural e possibilitar a abertura de uma intervenção antirracista.

Os trabalhos seguintes foram escritos por autores estrangeiros, alguns sendo tradução de artigos já publicados em seu idioma original, como no caso de O Ensino Sociológico nos Estabelecimentos de Ensino Médio: entre problemas sociais e sociologia acadêmica, de Elisabeth Chatel e Gérard Grosse, que se voltam para as tensões estabelecidas no Ensino de Sociologia nos liceus franceses, ainda que neste caso esta ciência encontre-se em meio às chamadas Ciências Econômicas e Sociais. Os autores chamam a atenção para o fato de que, o discurso de formação para a cidadania ganha visibilidade nos programas em detrimento de uma perspectiva mais científica dessa disciplina, o que pode ser percebido pela análise realizada em torno dos programas da disciplina sofrida nos últimos anos, que indica a íntima relação entre o Ensino e os chamados Problemas Sociais.

Partindo de um balanço socio-histórico Michael DeCesare produz uma análise do Ensino de Sociologia na High School (Ensino Médio) americana em 95 Anos de Ensino de Sociologia no Ensino Médio indo desde os primeiros programas de Sociologia para esse nível de ensino até 
as discussões contemporâneas promovidas pela Associação Americana de Sociologia. Surpreendentemente as análises de DeCesare chegam a conclusões próximas às pesquisas brasileiras e mesmo ao trabalho de Chatel e Grosse, ao apontar a predominância de um ensino para a cidadania em detrimento de uma formação científica, bem como a existência de professores despreparados, sem formação específica na área, e o fato dessa ser uma temática ainda pouco explorada pelos sociólogos, indicando ao final uma perspectiva não muito otimista.

Por fim, Diego Pereyra e Claudia Pontremoli, em ¿La Sociología está Pasada de Moda? Una discusión sobre la enseñanza de sociología en la escuela media en Argentina: docentes, estudiantes y propuesta curricular, se voltam para a realidade do Ensino de Sociologia em um país mais próximo, cuja realidade é igualmente desconhecida pela maioria dos pesquisadores brasileiros nesse campo. Assim como no Brasil, nos é apontado pelos autores um percurso marcado pela inclusão e exclusão dessa disciplina no currículo escolar argentino, todavia eles não se limitam a essa reflexão, voltando-se também para a análise da perspectiva de alunos e professores sobre o ensino dessa ciência.

$\mathrm{O}$ que se pode perceber ao analisarmos o conjunto desses trabalhos, considerando ainda a literatura existente nessa temática no Brasil, é que, por um lado temos uma ampliação das questões que vêm sendo debatidas no Brasil, emergindo uma pluralidade de abordagens possíveis para essa seara, por outro, que quando pensamos as pesquisas aqui desenvolvidas em uma perspectiva comparada com os demais trabalhos temos uma série de pontos em comum que podem surpreender o leitor. A ênfase na formação para a cidadania que historicamente atravessa 0 Ensino de Sociologia apesar dos elementos contingenciais possui, aparentemente, questões mais profundas que parecem estar enraizadas na própria natureza sociológica da sociologia, para usar a expressão de Fernandes (1980), assim como a íntima relação entre os programas a serem adotados em sala de aula e os fenômenos sociais que ocorrem.

Outras questões também se mostram relevantes para essa discussão, porém infelizmente não poderão ser abarcadas aqui, como os livros didáticos, o estágio supervisionado, o impacto do Programa Institucional de Bolsas de Iniciação à Docência (PIBID) nos cursos de Ciências Sociais, a presença da Sociologia nos vestibulares e no Exame Nacional do Ensino Médio (ENEM), as representações dessa disciplina entre professores e alunos etc., todavia a agenda de pesquisa continua em aberto, sendo um vasto campo ainda a ser explorado pelos pesquisadores.

É esperado que esse número possa contribuir para a solidificação do debate acadêmico em torno do Ensino de Sociologia, que vem se formando na interface entre o campo das Ciências Sociais e da Educação. O processo de ampliação dos diálogos, trazendo à tona novas pesquisas assim como a experiência do Ensino de Sociologia em outros contextos nacionais, possibilita repensar os contornos que o campo vem tomando e, certamente, trazer uma contribuição enfática para o campo das Ciências Sociais e da Educação. 
Apresentação da Seção Temática - Ensino de Sociologia

\section{Referências}

BRASIL. Lei no 9.394, de 20 de dezembro de 1996. Estabelece as diretrizes e bases da educação nacional. Diário Oficial da União, Brasília, 21 de dezembro de 1996.

BRASIL. Lei no 11.648, de 2 de junho de 2008. Altera o art. 36 da lei no 9.394, de 20 de dezembro de 1996, que estabelece as diretrizes e bases da educação nacional, para incluir a Filosofia e a Sociologia como disciplinas obrigatórias nos currículos do ensino médio. Diário Oficial da União, Brasília, 3 de junho de 2008.

BRASIL. Parecer CNE/CBE nº 38/2006. Inclusão obrigatória das disciplinas de Filosofia e Sociologia no currículo do Ensino Médio. Diário Oficial da União, Brasília, 14 de agosto de 2006.

FERNANDES, Florestan. A Natureza Sociológica da Sociologia. São Paulo: Ática, 1980.

HANDFAS, Anita. O Estado da Arte do Ensino de Sociologia na Educação Básica: um levantamento preliminar da produção acadêmica. Inter-legere, s/v, n. 9, p. 386-400, 2011.

LEITHAUSER, Thomas; WEBER, Silke. Ética, Moral e Política na Visão de Professores Brasileiros e Alemães. Estudos de Sociologia, v. 16, n. 1, p. 87-108, 2010. MEUCCI, Simone. Institucionalização da sociologia no Brasil: primeiros manuais e cursos. São Paulo: Hucitec: Fapesp, 2011.

MORAES, Amaury César. Ensino de Sociologia: periodização e campanha pela obrigatoriedade. Cadernos CEDES, Campinas, Universidade Estadual de Campinas, v. 31, n 85, p. 359-382, 2011.

OLIVEIRA, Amurabi. Revisitando a História do Ensino de Sociologia na Educação Básica. Acta Scientiarum. Education, Maringá, Universidade Estadual de Maringá, v. 35, n 2, p. 179-189, 2013.

SANTOS, Mário Bispo. A Sociologia no Contexto das Reformas do Ensino Médio. In: CARVALHO, Lejeune Mato Grosso de (Org.). Sociologia e Ensino em Debate: experiências e discussão de sociologia no ensino médio. Ijuí: Ed. Unijuí, 2004. P. 131-180.

SARANDY, Flávio. Ensino de Sociologia: insulamento e invisibilidade de uma disciplina. In: FIGUEIREDO, André Luiz de; OLIVEIRA, Luiz Fernandes; PINTO, Naylane Mendonça (Org.). Sociologia na Sala de Aula: reflexões e experiências docentes no Estado do Rio de Janeiro. Rio de Janeiro: Imperial Novo Milênio, 2012. P. 47-72.

SILVA, Ileizi Luciana Fiorelli. O Ensino das Ciências Sociais/Sociologia no Brasil: histórico e perspectivas. In: MORAES, Amaury César (Org.). Coleção Explorando o Ensino de Sociologia. Brasília: MEC, 2010. P. 23-31.

WEBER, Silke. O Professorado e o Papel da Educação na Sociedade. Campinas: Papirus, 1996.

Amurabi Pereira de Oliveira é licenciado e mestre em Ciências Sociais pela Universidade Federal de Campina Grande (UFCG), doutor em Sociologia pela Universidade Federal de Pernambuco (UFPE). Atualmente é professor da Universidade Federal de Alagoas, atuante em seu Programa de PósGraduação em Educação e líder do grupo de pesquisa Educação \& Ciências Sociais.

E-mail: amurabi_cs@hotmail.com 